\title{
Burden of cancer in Malawi; common types, incidence and trends: National population-based cancer registry
}

Kelias Phiri Msyamboza ${ }^{1,4^{*}}$, Charles Dzamalala ${ }^{2}$, Catherine Mdokwe ${ }^{3}$, Steve Kamiza $^{2}$, Marshal Lemerani $^{3}$, Titha Dzowela ${ }^{3}$ and Damson Kathyola ${ }^{3}$

\begin{abstract}
Background: Cancer is a leading cause of morbidity and mortality worldwide with a majority of cases and deaths occurring in developing countries. While cancer of the lung, breast, colorectum, stomach and prostate are the most common types of cancer globally, in east and southern Africa these are less common and comprehensive data to inform policies are lacking.

Methods: Nationwide cancer registry was conducted between September and October 2010 in Malawi. New cancer cases registered from 2007 to 2010 were identified from hospital and clinic registers of 81 out of 84 health facilities providing cancer diagnosis, treatment or palliative care services. Demographic and cancer data were extracted from registers and case notes using a standard form.

Results: A total of 18,946 new cases of cancer were registered in Malawi from 2007-2010. Of these 55.9\% were females, $7.2 \%$ were children aged less than 15 years, $76.5 \%$ were adults aged $15-59$ years and $16.4 \%$ were elderly aged 60 years or more. Only $17.9 \%$ of the cases had histologically verified diagnosis, 33.2\% were diagnosed clinically and $49.6 \%$ based on clinical and some investigations. Amongst females, cancer of the cervix was the commonest accounting for $45.4 \%$ of all cases followed by Kaposi sarcoma (21.1\%), cancer of the oesophagus (8.2\%), breast (4.6\%) and non-Hodgkin lymphoma (4.1\%). In males, Kaposi sarcoma was the most frequent (50.7\%) then cancer of oesophagus (16.9\%), non-Hodgkin lymphoma (7.8), prostate (4.0\%) and urinary bladder (3.7\%). Agestandardised incidence rate per 100,000 population for all types of cancer in males increased from 31 in 1999-2002 to 56 in 2007-2010. In females it increased from 29 to 69. Kaposi sarcoma and cancer of the oesophagus, cervical cancer and Kaposi sarcoma were the main causes for the increased incidence in males and females respectively. It was estimated that, annually at least 8,151 new cases of cancer (all types) occur in Malawi.
\end{abstract}

Conclusions: This study provided data on common types and trends of cancer that could be used to focus prevention, treatment and control interventions in the context of limited resources. The problem of underreporting and misdiagnosis of cancer cases has been highlighted.

Keywords: Cancer, Non-communicable diseases, Sub-Saharan Africa, Malawi

\section{Background}

Cancer is a leading cause of morbidity and mortality worldwide. In 2008, globally, there were 12.7 million new cancer cases and 7.6 million cancer deaths (around 13\% of all deaths) with $56 \%$ of the new cases and $63 \%$ of the cancer deaths occurring in developing countries. It is

\footnotetext{
* Correspondence: msyambozak@mw.afro.who.int

${ }^{1}$ World Health Organisation, Malawi Country Office, Lilongwe, Malawi

Full list of author information is available at the end of the article
}

projected that by 2030, the number of new cancer cases and deaths will increase by $69 \%$ and $72 \%$ to 21.4 million and 13.2 million respectively $[1,2]$. While cancer of the lung (12.7\%), breast (10.9\%), colorectum $(9.7 \%)$, stomach (7.8\%) and prostate $(7.2 \%)$ are the most common types of cancer globally $[1,2]$, in sub-Saharan Africa (SSA) these are less common. In eastern and southern Africa (ESA) where HIV prevalence is high, AIDS-defining cancers including Kaposi sarcoma, cervical cancer, and
C Biomed Central

(c) 2010 Msyamboza et al; licensee BioMed Central Ltd. This is an open access article distributed under the terms of the Creative Commons Attribution License (http://creativecommons.org/licenses/by/2.0), which permits unrestricted use, distribution, and reproduction in any medium, provided the original work is properly cited. 
non-Hodgkin lymphoma are the most common. In West Africa, cancer of the liver is the most common [3-6]. Prevalences of risk factors for cancer in ESA are high; HIV $10 \%$ or more, human papillomavirus $34 \%$, tobacco smoking and harmful use of alcohol particularly in men $25 \%$ and $19 \%$ respectively and overweight in women $28 \%$ or more [7-9]. Indoor smoke from household use of solid fuels and urban air pollution are other common cancer risk factors in this region [10]. Comprehensive data on the burden and trends of cancer to inform policies, strategies and interventions are lacking in most countries in eastern and southern African region. Between September and October 2010, a nationwide cancer registry was conducted to determine the magnitude, trends of cancer and its challenges in Malawi.

\section{Methods}

\section{Survey design, sites and data collection}

Malawi Cancer Registry was established in 1985 as a population-based cancer registry with the aim of maintaining high quality cancer surveillance system and promoting research on cancer through collaboration. Utilising the cancer registry system, a cross-sectional health facility-based nationwide survey was conducted. All district (secondary), central (tertiary) and main public and private hospitals providing cancer laboratory diagnosis, treatment, palliative care or referral services were eligible and mapped out as survey sites. A total of 84 (70 public, 6 private, 6 research and 2 non-governmental) facilities met the criteria. Of these, 81 (94.4\%) consented to take part and data were collected. Three facilities (all international research institutions) refused to take part. The reason for their refusal was that they needed clearance from their headquarters which was not granted. The other three research institutions were local and participated in this study. Cancer cases and deaths were identified from registers in outpatient department (OPD), inpatient wards (all wards available at the facility), clinics (all clinics available), laboratory, pharmacy, theatre and mortuary. Demographic and cancer data on the identified cancer cases or deaths were extracted using a standard form from Malawi Cancer Registry. Data were extracted for period 1 January 2007 to 31 August 2010. Data collection was conducted by trained health workers (nurses and clinical officers) from September to October 2010.

\section{Data management}

Data were entered, cleaned and analysed using World Health Organisation cancer registry software version 4 (Can Reg4). The software had ability to detect duplicates thereby reducing the risk of double counting of cases that might have visited several hospitals or same hospital at different times. It also had the ability to estimate the age-standardised incidence rates based on age-specific national population data. National population data disaggregated by 5 -year age groups and by sex was obtained from the Malawi National Statistics Office (NSO). The NSO data were entered and used to produce age-standardised incidence rates in Can Reg4. The existing data in the Malawi Cancer Registry database were used to produce trends of cancer from 1987-2010.

\section{Ethics statement}

Ethical approval was granted by the Malawi National Health Sciences Research and Ethics Committee. Written informed consent to extract data from hospital registers and records was obtained from directors of hospitals that participated in the study.

\section{Results}

\section{Characteristics of new cases of cancer and methods of diagnosis}

For the period 1 January 2007 to 31 August 2010, a total of 18,946 new cases of cancer were registered in 81 out of 84 main health facilities (public, non-governmental organisations, and private) in Malawi. Of these new cases, $55.9 \%$ were females, $7.2 \%$ were children aged less than 15 years, $76.5 \%$ were adults aged $15-59$ years and $16.4 \%$ were aged 60 years or more. Geographically, $13.4 \%$ of the new cases were from the northern, $35.0 \%$ from central and 51.6\% from southern region. By diagnosis, only $17.9 \%$ of the new cases were diagnosed based on histology, cytology or haematology laboratory findings, $33.2 \%$ were diagnosed clinically (based on history taking and physical examination) and $49.6 \%$ based on clinical and some investigations (radiology, screening tests such as prostate specific antigen test, cervical cancer screening using visual inspection with acetic acid). Only 137 (0.7\%) out of 18,946 cases had information on the stage of cancer at the time of diagnosis. Table 1 below shows number of registered new cases, method of diagnosis and geographical distribution of registered cancer cases in Malawi from 1987-2010.

\section{Common types of cancer in Malawi}

Of the 10,541 new cancer cases among females registered between 2007 and 2010, cancer of the cervix was the commonest accounting for $45.4 \%$ of all cases followed by Kaposi sarcoma (21.1\%), cancer of the oesophagus (8.2\%), breast $(4.6 \%)$ and non-Hodgkin lymphoma (4.1\%). In males, of the 8,314 new cases registered in the same period, Kaposi sarcoma was the commonest (50.7\%) followed by cancer of oesophagus (16.9\%), non-Hodgkin lymphoma $(7.8 \%)$, prostate $(4.0 \%)$ and urinary bladder (3.7\%). In both sexes (sample size 18,855), the top five common cancers were; Kaposi sarcoma (34.1\%), cancer of the cervix (25.4\%), oesophagus (12.0\%), non-Hodgkin lymphoma (5.7\%) and urinary bladder (2.9\%). Lung cancer was one of 
Table 1 Number of registered new cases, method of diagnosis and geographical distribution of cancer in Malawi: 1987-2010

\begin{tabular}{|c|c|c|c|c|c|c|c|c|c|c|c|c|}
\hline & \multicolumn{2}{|c|}{$1987-1990$} & \multicolumn{2}{|c|}{ 1991-1994 } & \multicolumn{2}{|c|}{ 1995-1998 } & \multicolumn{2}{|c|}{ 1999-2002 } & \multicolumn{2}{|c|}{ 2003-2006 } & \multicolumn{2}{|c|}{ 2007-2010 } \\
\hline & $\mathrm{n}$ & $\%$ & $\mathbf{n}$ & $\%$ & $\mathbf{n}$ & $\%$ & $\mathrm{n}$ & $\%$ & $\mathbf{n}$ & $\%$ & $\mathbf{n}$ & $\%$ \\
\hline \multicolumn{13}{|l|}{ New registered cancer cases: } \\
\hline Males & 2,335 & 46.4 & 2,276 & 49.5 & 2,576 & 51.3 & 3,983 & 50.5 & 6,850 & 49.8 & 8,360 & 44.1 \\
\hline Females & 2,699 & 53.6 & 2,326 & 50.5 & 2,447 & 48.7 & 3,901 & 49.5 & 6,914 & 50.2 & 10,586 & 55.9 \\
\hline Total & 5,034 & 100.0 & 4,602 & 100.0 & 5,023 & 100.0 & 7,884 & 100.0 & 13,764 & 100.0 & 18,946 & 100.0 \\
\hline \multicolumn{13}{|l|}{ Method of cancer diagnosis: } \\
\hline Clinical only & 0 & 0 & 405 & 8.8 & 924 & 18.4 & 2562 & 32.5 & 4515 & 32.8 & 6101 & 32.2 \\
\hline Clinical and some investigations & 1 & 0.01 & 341 & 7.4 & 1000 & 19.9 & 2278 & 28.9 & 5602 & 40.7 & 9397 & 49.6 \\
\hline Histology/haematology/cytology & 5033 & 99.9 & 3856 & 83.8 & 3099 & 61.7 & 3043 & 38.6 & 3647 & 26.5 & 3448 & 18.2 \\
\hline Total & 5034 & 100.0 & 4602 & 100.0 & 5023 & 100.0 & 7884 & 100.0 & 13764 & 100.0 & 18946 & 100.0 \\
\hline \multicolumn{13}{|l|}{ Cancer cases by region: } \\
\hline Northern & 35 & 6.8 & 433 & 9.4 & 312 & 6.2 & 603 & 7.7 & 880 & 6.4 & 2538 & 13.4 \\
\hline Central & 137 & 26.6 & 1,261 & 27.4 & 1,006 & 20.0 & 1,347 & 17.2 & 3,478 & 25.3 & 6,630 & 35.0 \\
\hline Southern & 343 & 66.6 & 2,909 & 63.2 & 3,711 & 73.8 & 5,883 & 75.1 & 9,389 & 68.3 & 9,775 & 51.6 \\
\hline Total & 515 & 100.0 & 4,603 & 100.0 & 5,029 & 100.0 & 7,833 & 100.0 & 13,747 & 100.0 & 18,944 & 100.0 \\
\hline
\end{tabular}

$\mathrm{n}=$ number of registered new cancer cases, $\%=$ percentage

the least common accounting for only $0.2 \%$ of all cancers in both sexes, $0.2 \%$ and $0.1 \%$ in males and females respectively. In children under 15 years of age, of the 1,280 registered new cases, non-Hodgkin lymphoma (mainly Burkitt's) was the commonest accounting for $56.4 \%$ followed by Kaposi sarcoma (15.0\%), cancer of the eye (7.3\%), kidney (4.5\%) and bone (2.2\%). Of the 13,660 registered new cancer cases aged 15-59 years (both sexes), 41.3\% had Kaposi sarcoma, 28.3\% had cervical cancer, 9.4\% had cancer of the oesophagus, $2.6 \%$ breast and $2.6 \%$ had eye cancer. In the elderly (age 60 years or more), common cancers were; oesophagus (28.7\%), cervix (24.0\%), Kaposi sarcoma (10.0\%) and prostate (7.7\%). Table 2 summarises the common types of cancer by gender and age.

\section{Age-standardised incidence}

In males, age-standardised incidence rate (ASR) per 100,000 population per year was estimated at 55.5 while in females was 68.8 for all types of cancer. Kaposi sarcoma, cancer of the oesophagus, prostate, non-Hodgkin and urinary bladder were the top five cancers in males with ASR of 25.4, 12.4, 3.3, 2.5 and 2.5 respectively. In females, cancer of the cervix, Kaposi sarcoma, cancer of the oesophagus, breast and non-Hodgkin lymphoma were the top five with ASR of 33.6, 11.9, 6.8, 3.5 and 1.7 respectively. Based on these estimated ASR and age, sex disaggregated national population data from national statistical office, it was estimated that annually, there were at least 8,151 new cases of cancer (all types); 2,408 Kaposi sarcoma, 1,236 cervical cancer, 549 oesophageal cancer, 273 non-Hodgkin lymphoma, and 273 urinary bladder cancer cases in Malawi (Table 3, Figure 1 and Figure 2).

\section{Trends of age-standardised incidence}

Age-standardised incidence of cancer per 100,000 population per year (all types) in males increased from 31.0 in 1999-2002 to 51.4 in 2003-2006 to 55.5 in 2007-2010. Kaposi sarcoma and cancer of the oesophagus had the highest increase in ASR which increased from 10.9 to 18.2 to 25.3 ; 5.5 to 11.1 to 12.4 respectively. In females, ASR increased from 28.8 to 50.5 to 68.8 for all types of cancer with the major increase in cervical cancer and Kaposi sarcoma of 9.8 to 19.6 to $33.6 ; 5.1$ to 8.5 to 11.9 respectively (Figure 3 and Figure 4).

\section{Discussion}

This national cancer registry study demonstrated that cancer is an important public health problem and incidence was increasing in Malawi. Kaposi sarcoma, cancer of the cervix and cancer of the oesophagus were the major cause of the increasing trend. With high HIV prevalence of $10.6 \%$ [11], the increase is Kaposi sarcoma and cervical cancer was in agreement with the findings from other studies $[12,13]$. The active case finding was more extensive in this survey providing more complete national data than previously reported.

The introduction and scaling up of free HIV antiretroviral therapy (ART) programme and insecticide-treated bednets (ITN) in 2003 did not seem to have an impact on the trends of Kaposi sarcoma, cervical cancer and Burkitt's lymphoma respectively as suggested by studies from other countries $[13,14]$. This could suggest that higher ART and ITN coverages are required to show impact on HIV and malaria related cancers than the current (2010) 65\% coverage of estimated population in need of ART and $40 \%$ 
Table 2 Common types of registered new cancer cases by gender and age in Malawi: 2007-2010

\begin{tabular}{|c|c|c|c|c|c|c|c|c|c|c|c|c|}
\hline \multirow[t]{2}{*}{ Cancer type } & \multicolumn{2}{|c|}{ Males } & \multicolumn{2}{|c|}{ Females } & \multicolumn{2}{|c|}{ Both sexes } & \multicolumn{2}{|c|}{$\begin{array}{l}\text { Children under } 15 \\
\text { years old }\end{array}$} & \multicolumn{2}{|c|}{$\begin{array}{l}\text { Adults aged } 15- \\
59 \text { years }\end{array}$} & \multicolumn{2}{|c|}{$\begin{array}{l}\text { Elderly aged } 60 \\
\text { years or more }\end{array}$} \\
\hline & $\%$ & (n) & $\%$ & (n) & $\%$ & (n) & $\%$ & (n) & $\%$ & (n) & $\%$ & (n) \\
\hline Lung & 0.2 & (19) & 0.1 & (14) & 0.2 & (33) & - & - & 0.1 & (19) & 0.3 & (10) \\
\hline Breast & 0.3 & (26) & 4.6 & $(480)$ & 2.7 & (506) & - & - & 2.6 & (357) & 3.7 & (109) \\
\hline Kidney & 0.4 & (34) & 0.4 & (41) & 0.4 & (75) & 4.5 & (58) & 0.1 & (13) & 0.2 & (6) \\
\hline Penis & 1.4 & $(117)$ & - & - & 0.6 & (117) & - & - & 0.6 & (80) & 0.9 & (26) \\
\hline Liver & 1.5 & $(121)$ & 0.7 & (70) & 1.0 & (191) & 1.5 & (19) & 0.9 & (124) & 1.2 & (36) \\
\hline Ovary & - & - & 0.9 & (99) & 0.5 & (99) & - & - & 0.5 & (72) & 0.5 & (15) \\
\hline Bone & 1.6 & (129) & 1.2 & (123) & 1.3 & (252) & 2.2 & (28) & 1.3 & (174) & 1.0 & (29) \\
\hline Stomach, intestine, rectum, anus & 1.8 & $(147)$ & 1.4 & (152) & 1.6 & (299) & - & - & 1.3 & $(179)$ & 4.1 & $(121)$ \\
\hline Eye & 2.7 & $(225)$ & 2.5 & $(266)$ & 2.6 & (491) & 7.3 & (94) & 2.6 & (352) & 1.0 & (30) \\
\hline Urinary bladder & 3.7 & (308) & 2.2 & $(232)$ & 2.9 & (540) & 0.5 & (7) & 2.2 & $(300)$ & 5.1 & $(149)$ \\
\hline Prostate & 4.0 & (332) & - & - & 1.8 & (332) & - & - & 0.5 & (70) & 7.7 & $(226)$ \\
\hline Non-Hodgkin lymphoma & 7.8 & $(649)$ & 4.1 & $(427)$ & 5.7 & $(1,076)$ & 56.4 & $(722)$ & 2.1 & $(289)$ & 1.3 & (37) \\
\hline Oesophagus & 16.9 & $(1,406)$ & 8.2 & (862) & 12.0 & $(2,268)$ & - & - & 9.4 & $(1,286)$ & 28.7 & (838) \\
\hline Cervix & - & - & 45.4 & $(4,787)$ & 25.4 & $(4,787)$ & - & - & 28.3 & $(3,869)$ & 24.0 & $(701)$ \\
\hline Kaposi sarcoma & 50.7 & $(4,213)$ & 21.1 & $(2,225)$ & 34.1 & $(6,438)$ & 15.0 & (192) & 41.3 & $(5,642)$ & 10.0 & (291) \\
\hline Others & 7.1 & (588) & 7.2 & $(763)$ & 7.2 & $(1,351)$ & 12.5 & $(160)$ & 6.1 & (834) & 10.2 & (297) \\
\hline Total & 100.0 & $(8,314)$ & 100.0 & $(10,541)$ & 100.0 & $(18,855)$ & 100.0 & $(1,280)$ & 100.0 & 13,660 & 100.0 & $(2,921)$ \\
\hline
\end{tabular}

$\mathrm{n}=$ number of cancer cases in the group, $\%$ = percentage

insecticide-treated bed net use in children under the age of five years $[11,15]$. For cancer of the oesophagus, it was not known why the trend was increasing. High HIV prevalence was less likely because the association between cancer of the oesophagus and HIV/AIDS is not well established although both may be related to fumonisin, a mycotoxin found in maize [16]. Increase in smoking, consumption of alcohol and maize contaminated with fumonisin could be some of the factors contributing to the increase in incidence of oesophageal cancer $[7,16,17]$.

Table 3 Age-standardised incidence rate and estimated annual number of registered new cancer cases by gender in Malawi

\begin{tabular}{|c|c|c|c|c|c|}
\hline & \multicolumn{2}{|c|}{$\begin{array}{l}\text { Age standardised cancer } \\
\text { incidence rate per } 100,000 \\
\text { population per year }\end{array}$} & \multicolumn{2}{|c|}{$\begin{array}{l}\text { Estimated annual } \\
\text { number of new cancer } \\
\text { cases }\end{array}$} & \multirow[t]{2}{*}{ Estimated total annual number of new cancer cases } \\
\hline & Males & Females & Males & Females & \\
\hline Lung & 0.2 & 0.1 & 4 & 2 & 6 \\
\hline Penis & 0.9 & - & 31 & - & 31 \\
\hline Liver & 0.8 & 0.4 & 51 & 27 & 78 \\
\hline Ovary & - & 0.6 & - & 40 & 40 \\
\hline Bone & 0.7 & 0.7 & 45 & 47 & 92 \\
\hline Stomach, intestine, rectum, anus & 0.7 & 1.2 & 19 & 36 & 55 \\
\hline Eye & 1.3 & 1.4 & 83 & 94 & 177 \\
\hline Urinary bladder & 2.5 & 1.7 & 159 & 114 & 273 \\
\hline Prostate & 3.3 & - & 73 & - & 73 \\
\hline Non-Hodgkin lymphoma & 2.5 & 1.7 & 159 & 114 & 273 \\
\hline Breast & - & 3.5 & - & 106 & 106 \\
\hline Oesophagus & 12.4 & 6.8 & 343 & 206 & 549 \\
\hline Kaposi sarcoma & 25.4 & 11.9 & 1,609 & 799 & 2,408 \\
\hline Cervix & - & 33.6 & - & 1,236 & 1,236 \\
\hline All types & 55.5 & 68.8 & 3,529 & 4,622 & 8,151 \\
\hline
\end{tabular}




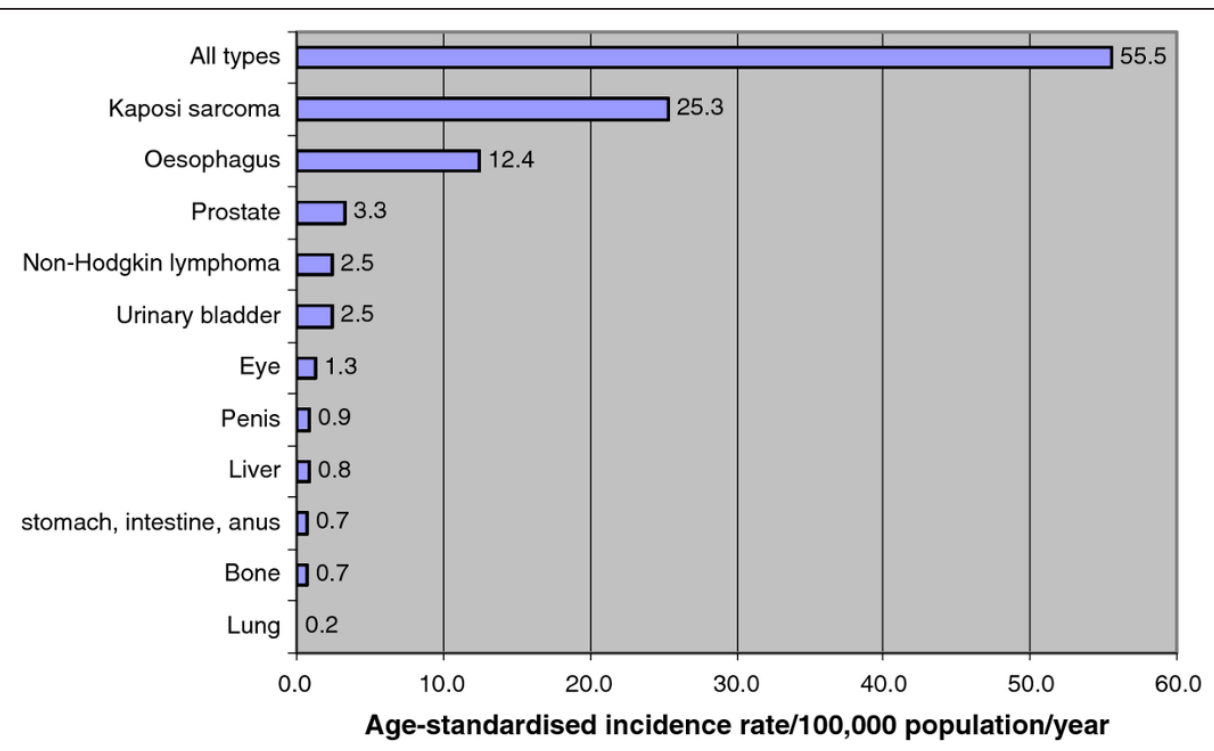

Figure 1 Cancer age-standardised incidence rate in males in Malawi: 2007-2010.

Lung cancer, the world's most frequent cancer in males, is generally reported to be less common in sub-Saharan Africa $[3,18,19]$ although tobacco smoking is common with prevalence of at least $25 \%$ in men [7]. The reasons for relatively low prevalence of lung cancer in the presence of high prevalence of tobacco smoking in sub-Saharan Africa are unknown. Under-reporting, misdiagnosis, competing high levels of HIV/AIDS related cancers could be the possible explanations $[18,20,21]$.

Our findings on the significance of gender and age differences for Kaposi sarcoma, cancer of oesophagus and non-Hodgkin lymphoma being more common in males than females, cancer of the oesophagus in people aged 60 years or more, and Kaposi sarcoma and nonHodgkin lymphoma, in particular Burkitt's, being the most common cancers in children under 15 years of age were consistent with other studies [22-25]. Two thirds $(67.1 \%)$ of non-Hodgkin lymphoma cases were children aged less than 15 years old. As countries in sub-Saharan Africa implement universal coverage of ART and ITNs, there would be need to monitor the trends of HIV and malaria related cancers as one way of assessing other public health benefits of these interventions.

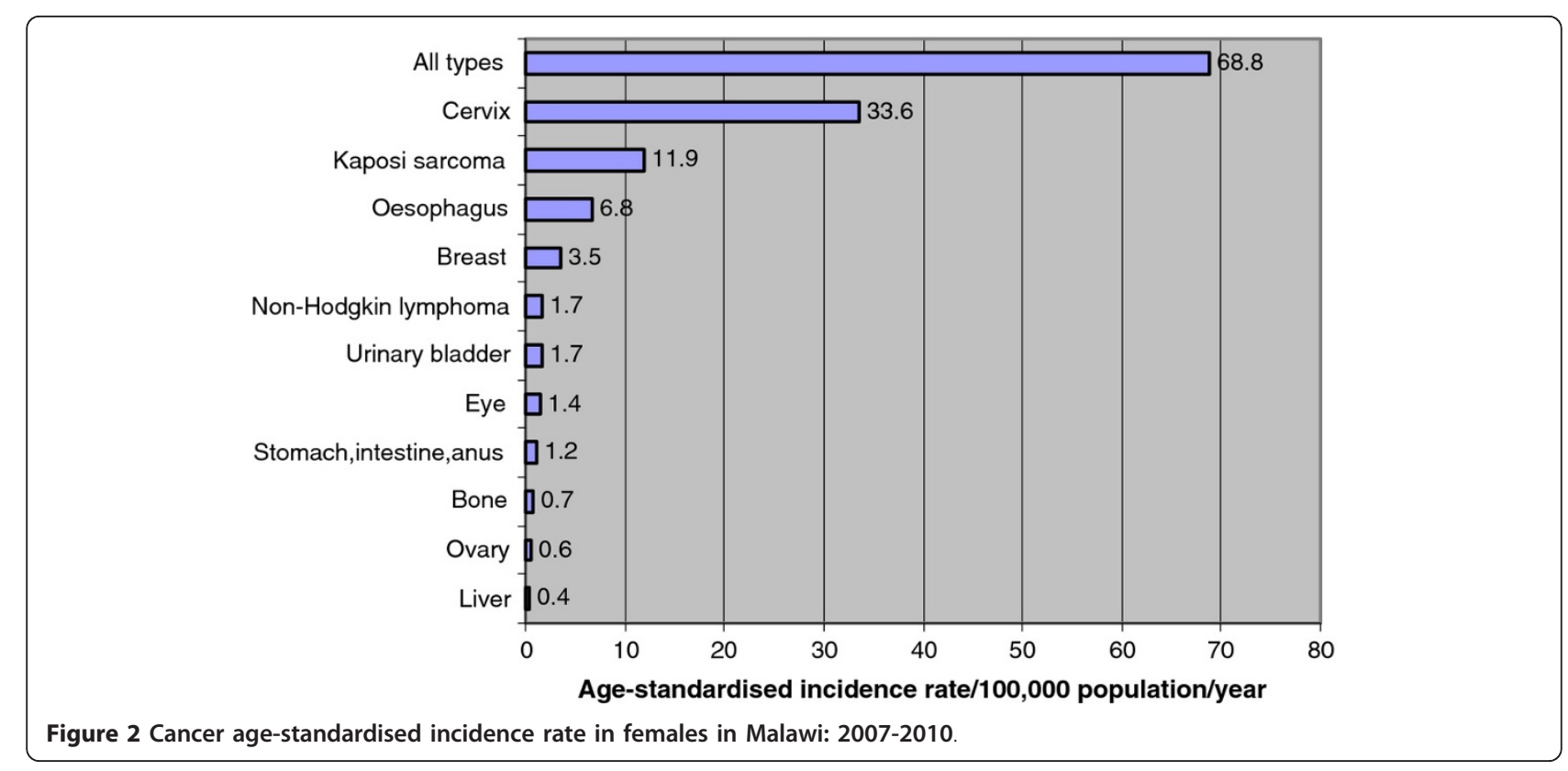




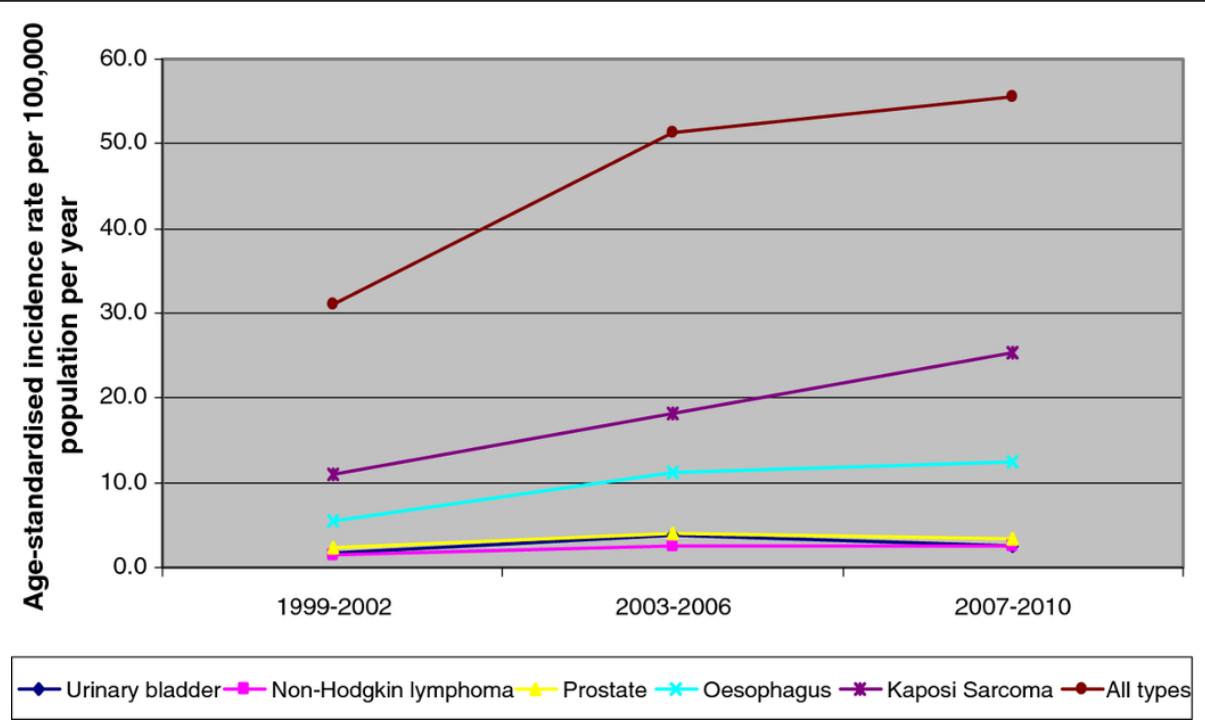

Figure 3 Trends in cancer incidence in males in Malawi: 1999-2010.

The Malawi Ministry of Health, through Sexual and Reproductive Health Unit, implemented a screen-andtreat programme for cervical cancer using visual inspection with acetic acid (VIA) approach. The programme started in 2004 and targeted women aged 30-50 years old. As of June 2011, there were a total of 81 health facilities providing cervical cancer services (50 VIA only, 29 VIA and cryotherapy and 2 VIA, cryotherapy, loop electrosurgical excision procedure (LEEP) and major surgery). Cumulatively, a total of 59,217 women were screened, 5,744 (9.7\%) were VIA positive and 1,777 (3.0\%) had suspected cervical cancer [26]. This study demonstrated that
$12.0 \%$ and $32.1 \%$ of cervical cancer cases were aged $20-29$ years and 50 years or more respectively. This would suggest that the VIA Programme in Malawi could be missing at least $44 \%$ of women with cervical cancer. Data on population-based, age-specific prevalence of Human papillomavirus (HPV), the virus that causes cervical cancer is not available in Malawi. However, WHO estimates that the overall HPV prevalence is about 34\% [27]. Studies from other countries reported HPV prevalence in women having two peaks, one at 15-29 year age group and the other at $60-69$ year age group $[28,29]$. This, together with high HIV prevalence could be some of the reasons for cervical

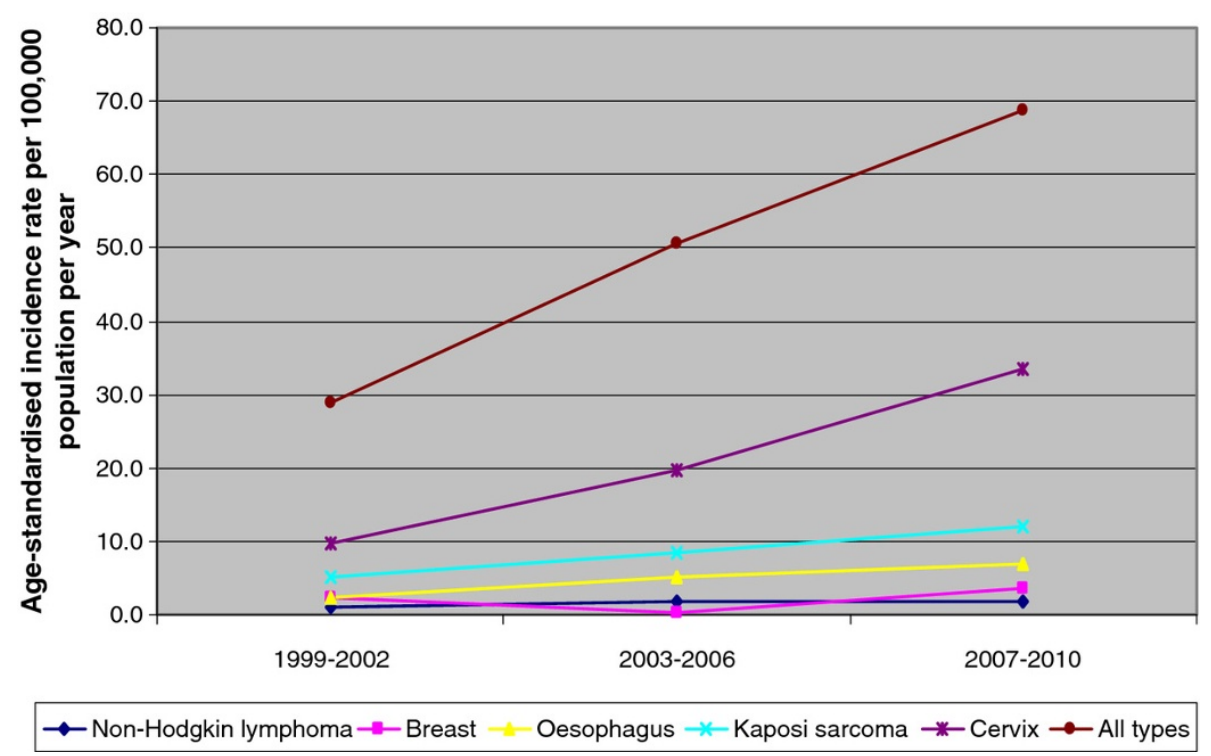

Figure 4 Trends in cancer incidence in females in Malawi: 1999-2010. 
cancer occurrence in young and older age groups. Cervical cancer screening is the only established public health cancer screening programme in Malawi. Breast (mammography) and prostate (prostate-specific antigen test and digital rectal examination) cancer screening were available in only one private hospital. This private hospital participated in the study. Lung cancer was not routinely screened. Introduction of other cancer screening services in addition to cervical cancer in public health facilities could enhance early detection and treatment.

This study also revealed that only $18 \%$ of the cancer cases had laboratory verified diagnosis. Inadequate laboratory capacity (only one public and one private histology laboratory, all in Blantyre), long waiting time to get histology results, confidence of health workers in diagnosing some cancers clinically, in particular Kaposi sarcoma (the commonest cancer), late presentation of patients to health facility and lack of treatment, in particular, chemotherapy and radiotherapy could be some of the factors leading to low laboratory verified diagnosis. The low level of laboratory verified cases would suggest that the reported number of cancer cases was likely to be under-estimated because of under diagnosis and missing of cancer cases [21]. Current WHO estimates suggest that every year there are at least 2,316 new cases of cervical cancer cases in Malawi [27] while estimate from this study was 1,236 . This illustrated that the reported number of registered new cervical cancer cases was only $53 \%$ of the actual problem at the community level. Some of the possible reasons for underdetection of cervical cancer cases could be low coverage of the screening programme (3.7\% of the target group) and low specificity of VIA although it is the cost-effective screening method recommended for resource-limited settings and is comparable to Pap smear [27,30-32]. Despite the under-reporting, population-based cancer registry is the cost-effective method of collecting comprehensive data on cancer that resource-poor countries in sub-Saharan Africa are being encouraged to establish [33].

About half (52\%) of registered new cancer cases (all types of cancer) were from the southern region with central and northern region accounting for 35\% and $13 \%$ respectively. Population distribution was less likely to be the main reason as distribution was similar in the south and centre at $45 \%$ and $42 \%$ respectively [34]. The extent of active case finding in this survey was similar in all the regions whereby as many health facilities as possible were visited. Availability of diagnostic services hence less specimen transport cost and waiting time for results, cancer registry office and high HIV prevalence (south $18 \%$, centre $10 \%$, and north $8 \%$ ) in the southern region were likely to be some of the contributing factors [11].

Data on lifestyles (tobacco smoking and alcohol consumption) and HIV status were not available. Some of the registers, particularly in public facilities were missing. These were the limitations of this study. These limitations apply to all studies that utilise available health facility data in general. Another limitation of this study was the refusal by three international research institutions to participate in this study. The reason for their refusal was that they had to seek clearance from their headquarters which was not granted. However, all the three international research institutions were housed within the public hospital and were recruiting cases from outpatient department or wards. In addition, all the institutions sent specimens to National Histopathology Laboratory which participated in this study. It was therefore less likely that non-participation of these three international research institutions had significant effect on the results as most of cases were likely to be captured either from public hospital registers where cases were first registered or from histology laboratory where specimens were sent or both. The use of clinical diagnosis only, cancer screening tests such as VIA and prostate specific antigen (PSA) have their own limitations but these limitations were beyond this study. This study only collected and analysed data that were already there. Nevertheless, the comprehensive analysis of the burden of cancer and its challenges demonstrated by this study provided local evidence that could be used to inform policies, strategies and interventions for prevention and control of cancer in Malawi, eastern and southern African region.

\section{Conclusion}

Cancer is a public health problem and the trend is increasing in Malawi, a poor country in eastern and southern Africa. Scaling up and/or improving the quality of cervical and breast cancer screening programmes, laboratory verified diagnosis, chemotherapy and radiotherapy treatment and introduction of human papillomavirus vaccine for cervical cancer control could be some of cancer prevention, treatment and control interventions that Malawi and other countries in eastern and southern Africa may consider to strengthen or adopt.

\section{Acknowledgements}

We are grateful to District Health Officers, Directors of Central Hospitals and Directors of Private Hospitals and Research Institutions for allowing their health facilities to participate in the study.

Funding

This study was funded by World Health Organisation allotment number AF. MAL.AAG.000.XU.10. The funders had no role in the study design, data collection and analysis, decision to publish, or preparation of the manuscript.

\section{Author details}

World Health Organisation, Malawi Country Office, Lilongwe, Malawi.

${ }^{2}$ University of Malawi, College of Medicine, Histopathology Department, Blantyre, Malawi. ${ }^{3}$ Ministry of Health, Lilongwe, Malawi. ${ }^{4}$ World Health Organisation, Malawi Country Office, ADL House, 2nd Floor, City Centre, P.O. Box 30390 Lilongwe 3, Malawi. 


\section{Authors' contributions}

Conceived and designed the study: KPM, CD, CM. Performed the study: KPM, $C D, C M, S K, T D, M L$, DK. Analyzed the data: KPM, CD, CM. Contributed reagents/materials/analysis tools: KPM, CD. Wrote the paper: KPM, CD, CM, SK, TD, ML, DK. All authors read and approved the final manuscript.

\section{Competing interests}

The authors declare that they have no competing interests.

Received: 28 October 2011 Accepted: 16 March 2012

Published: 16 March 2012

\section{References}

1. World Health Organization International Agency for Research on Cancer (IARC): Globocan 2008 Report IARC: Lyon; 2008, 2008.

2. World Health Organization: Cancer fact sheet no. 297. Geneva: World Health Organization; 2011.

3. Parkin DM, Ferlay J, Hamdi-Cherif M, Sitas F, Thomas J, Wabinga H, Whelan $S$ L: Cancer in Africa: Epidemiology and Prevention. Lyon, France: International Agency for Research on Cancer; 2003.

4. Casper C: The increasing burden of HIV-associated malignancies in resource-limited regions. Annu Rev Med 2011, 62:157-170.

5. Sitas F, Parkin M, Chirenje Z, Stein L, Mqoqi N, Wabinga H: Disease and Mortality in Sub-Saharan Africa. 2 edition. Washington (DC): World Bank; 2006.

6. Venook AP, Papandreou C, Furuse J, de Guevara LL: The incidence and epidemiology of hepatocellular carcinoma: a global and regional perspective. Oncologist 2010, 15(Suppl 4):5-13.

7. Msyamboza KP, Ngwira B, Dzowela T, Mvula C, Kathyola D, Harries AD, Bowie C: The Burden of Selected Chronic Non-Communicable Diseases and Their Risk Factors in Malawi: Nationwide STEPS Survey. PLoS One 2011, 6(5):e20316.

8. Damasceno A, Azevedo A, Silva-Matos C, Prista A, Diogo D, Lunet N Hypertension prevalence, awareness, treatment, and control in Mozambique: urban/rural gap during epidemiological transition. Hypertension 2009, 54(1):77-83.

9. Nsakashalo-Senkwe M, Siziya S, Goma FM, Songolo P, Mukonka V, Babaniyi O: Combined prevalence of impaired glucose level or diabetes and its correlates in Lusaka urban district, Zambia: a population based survey. Int Arch Med 2011, 4(1):2.

10. Dalal S, Beunza JJ, Volmink J, Adebamowo C, Bajunirwe F, Njelekela M, Mozaffarian D, Fawzi W, Willett W, Adami HO, Holmes MD: Noncommunicable diseases in sub-Saharan Africa: what we know now. Int $\mathrm{J}$ Epidemiol 2011, 40(4):885-901.

11. Office Malawi National Statistical: Demographic Health Survey 2010 Nationa Statistical Office: Zomba; 2011.

12. Mutalima N, Molyneux EM, Johnston WT, Jaffe HW, Kamiza S, Borgstein E, Mkandawire N, Liomba GN, Batumba M, Carpenter LM, Newton R: Impact of infection with human immunodeficiency virus-1 (HIV) on the risk of cancer among children in Malawi - preliminary findings. Infect Agent Cancer 2010, 5:5.

13. Bower M, Palmieri $C$, Dhillon T: AIDS-related malignancies: changing epidemiology and the impact of highly active antiretroviral therapy. Curr Opin Infect Dis 2006, 19(1):14-19.

14. Geser A, Brubaker G, Draper CC: Effect of a malaria suppression program on the incidence of African Burkitt's lymphoma. Am J Epidemiol 1989, 129(4):740-752.

15. Malawi Ministry of Health: Malawi Antiretroviral treatment Pogramme Quarterly Report: $1^{\text {st }}$ Quarter 2011. Lilongwe. Ministry of Health 2011.

16. Williams JH, Grubb JA, Davis JW, Wang JS, Jolly PE, Ankrah NA, Ellis WO, Afriyie-Gyawu E, Johnson NM, Robinson AG, Phillips TD: HIV and hepatocellular and esophageal carcinomas related to consumption of mycotoxin-prone foods in sub-Saharan Africa. Am J Clin Nutr 2010, 92(1):154-160.

17. Mlombe Y, Dzamalala C, Chisi J, Othieno-Abinya N: Oesophageal cancer and Kaposi's sarcoma in Malawi: a comparative analysis. Malawi Med J 2009, 21(2):66-68.

18. Reeve PA: Lung cancer in Malawi: experience of bronchoscopy in Zomba General Hospital. Cent Afr J Med 1989, 35(3):355-358.

19. Jemal A, Bray F, Center MM, Ferlay J, Ward E, Forman D: Global cancer statistics. CA Cancer J Clin 2011, 61(2):69-90.
20. Segal I, Ally R, Mitchell H: Gastric cancer in sub-Saharan Africa. Eur J Cancer Prev 2001, 10(6):479-482.

21. Banda LT, Parkin DM, Dzamalala CP, Liomba NG: Cancer incidence in Blantyre, Malawi 1994-1998. Trop Med Int Health 2001, 6(4):296-304.

22. Phipps W, Ssewankambo F, Nguyen H, Saracino M, Wald A, Corey L, Orem J, Kambugu A, Casper C: Gender differences in clinical presentation and outcomes of epidemic Kaposi sarcoma in Uganda. PLoS One 2010, 5(11):e13936.

23. Mosam A, Aboobaker J, Shaik F: Kaposi's sarcoma in sub-Saharan Africa: a current perspective. Curr Opin Infect Dis 2010, 23(2):119-123.

24. Naresh KN, Raphael M, Ayers L, Hurwitz N, Calbi V, Rogena E, Sayed S, Sherman O, Ibrahim HA, Lazzi S, Mourmouras V, Rince P, Githanga J, Byakika B, Moshi E, Durosinmi M, Olasode BJ, Oluwasola OA, Akang EE, Akenòva Y, Adde M, Magrath I, Leoncini L: Lymphomas in sub-Saharan Africa - what can we learn and how can we help in improving diagnosis, managing patients and fostering translational research? $\mathrm{Br} J$ Haematol 2011, doi: 10.1111/j.1365-2141.2011.08772.x.

25. Mlotha J, Naidoo S: Oro-facial manifestations of Burkitt's lymphoma: an analysis of 680 cases from Malawi. ADJ 2011, 66(2):77-79.

26. Ministry of Health- Sexual and Reproductive Health Services: VIA Programme Report June 2011. Lilongwe, Mininstry of Health 2011.

27. World Health Organization: WHO/ICO Information Centre on HPV and Cervical Cancer (HPV Information Centre): Summary Report 2010. Geneva: World Health Organization; 2010.

28. Gage JC, Ajenifuja KO, Wentzensen NA, Adepiti AC, Eklund C, Reilly M, Hutchinson M, Wacholder S, Harford J, Soliman AS, Burk RD, Schiffman M: The age-specific prevalence of human papillomavirus and risk of cytologic abnormalities in rural nigeria: Implications for screen-and-treat strategies. Int J Cancer 2011, doi: 10.1002/ijc.26211.

29. Smith JS, Melendy A, Rana RK, Pimenta JM: Age-specific prevalence of infection with human papillomavirus in females: a global review. $J$ Adolesc Health 2008, 43(4 Suppl):S5-25-e1-41.

30. Sahasrabuddhe V, Parham G, Mwanahamuntu M, Vermund S: Cervical Cancer Prevention in Low- and Middle-Income Countries: Feasible, Affordable, Essential. Cancer Prev Res (Phila) 2011.

31. Mabeya H, Khozaim K, Liu T, Orango O, Chumba D, Pisharodi L, Carter J, Cu-Uvin S: Comparison of Conventional Cervical Cytology Versus Visual Inspection With Acetic Acid Among Human Immunodeficiency VirusInfected Women in Western Kenya. Low Genit Tract Dis 2011.

32. Sankaranarayanan R, Nessa A, Esmy PO, Dangou JM: Visual inspection methods for cervical cancer prevention. Best Pract Res Clin Obstet Gynaecol 2011

33. Okobia MN: Cancer care in sub-Saharan Africa - Urgent Need for Population-based Cancer Registries. Ethiop J Health Dev 2003, 17(2):89-98.

34. Office Malawi National Statistical: Population and Housing Census 2008 Zomba Office: National Statistical; 2008.

doi:10.1186/1756-0500-5-149

Cite this article as: Msyamboza et al:: Burden of cancer in Malawi; common types, incidence and trends: National population-based cancer registry. BMC Research Notes 2012 5:149.

\section{Submit your next manuscript to BioMed Central and take full advantage of:}

- Convenient online submission

- Thorough peer review

- No space constraints or color figure charges

- Immediate publication on acceptance

- Inclusion in PubMed, CAS, Scopus and Google Scholar

- Research which is freely available for redistribution 